\title{
Beyond the bench and bedside: Health literacy is fundamental to sustainable health and development
}

\author{
Gillian P. Christie ${ }^{\mathrm{a}}$ and Scott C. Ratzan ${ }^{\mathrm{b}, *}$ \\ ${ }^{a}$ Doctor of Public Health (DrPH) Candidate, Harvard T.H. Chan School of Public Health, Harvard \\ University, USA \\ ${ }^{\mathrm{b}}$ Senior Fellow, Mossavar-Rahmani Center for Business and Government Kennedy School, Harvard \\ University, USA
}

\begin{abstract}
Thirty years after the Ottawa Charter for Health Promotion, the 2030 Agenda for Sustainable Development - predicated on seventeen Sustainable Development Goals (SDGs) - were unveiled to the global community. Health literacy is an essential precondition and indicator of achieving the SDGs. Efforts to define and describe health literacy within public health and medicine have identified that the skills and abilities of many populations are inadequate to navigate the demands and complexity of health and healthcare. The authors suggest health literacy must move beyond the bench and bedside in clinical practice to achieve the aspirations and objectives of the SDGs.

This report synthesizes major developments in health literacy and draws from related disciplines to propose opportunities and future directions to improve health literacy across the lifespan. It introduces the cases of early childhood vaccinations; alcohol intake in adolescence; and dementia care in older adults to demonstrate the need for health literacy across the life course. It also draws on digital health data and technology and multisectoral partnerships to define the future of health literacy. The authors believe these approaches can and will lead to unlikely collaborations that advance health and well-being throughout and beyond the 2030 Agenda for Sustainable Development.
\end{abstract}

Keywords: Health literacy, communications, digital health technology, data-driven approaches, multisectoral engagement

\section{Introduction}

In 1986, Member States of the United Nations congregated in Ottawa, Canada for the First International Conference on Health Promotion. Its seminal output was the Ottawa Charter for Health Promotion, which included provisions to achieve Health for All by the year 2000 and beyond [1]. Thirty years later in 2016, the global community pledged support to the United Nations 2030 Sustainable Development Agenda. Seventeen Sustainable Development Goals (SDGs) were advanced to help facilitate coordinated action to end poverty, protect the planet, and ensure peace and prosperity [2]. With regards to human health, the third SDG focuses on advancing "good health and well-being" [2].

\footnotetext{
* Corresponding author: Scott C. Ratzan, Senior Fellow, Mossavar-Rahmani Center for Business and Government, Harvard Kennedy School, Weil Hall, 79 JFK Street, Cambridge, MA. USA. E-mail: scott_ratzan@hks.harvard.edu.
}

0167-5265/19/\$35.00 @ 2019 - IOS Press and the authors.

This article is published online with Open Access and distributed under the terms of the Creative Commons Attribution Non-Commercial License (CC BY-NC 4.0). 
While not explicitly included in the indicators or targets of the SDGs, health literacy - defined as "the degree to which individuals have the capacity to obtain, process, and understand basic health information and services needed to make appropriate health decisions" - is essential to achieving the economic, environmental, and social ambitions of the SDGs [3]. Better health literacy across all populations underpins improvements in the other SDGs, including eradication of poverty and hunger, quality education, and reduced inequalities [4]. Achieving the SDGs will require a dedicated focus on health literacy by all actors in global partnership to ensure no one is left behind and to deliver universal health coverage.

Despite increased multisectoral interest and compelling scientific evidence regarding the effectiveness of health literacy, the inadequacy of the skills and abilities of individuals to navigate the demands and complexity of health and healthcare persists. While these concerns affect communities in the United States (U.S.) and many other high-income countries, the gap is particularly acute in low- and middle-income countries (LMICs) that are often characterized by underdeveloped health systems. Within both contexts, the ability for individuals to prevent and manage complex and costly diseases is limited by poor health literacy. Beyond the individual, however, equal attention must be targeted on governments and healthcare systems to provide accurate and accessible health information [4].

Realizing the need for improved health literacy in achieving the SDGs during the next thirty years and beyond, this chapter synthesizes major developments and proposes opportunities and future directions for health literacy across the lifespan. It uses the cases of early childhood vaccinations; alcohol use in adolescence; and dementia care in older adults to demonstrate the need to develop health literacy across the life course. It also draws on digital health data and technology and multisectoral partnerships to define the future of health literacy. The authors believe this can and will lead to unlikely collaborations that advance health and well-being throughout and beyond the 2030 Agenda for Sustainable Development.

\section{Moving beyond definitions and research}

Since the turn of the 21st Century, health literacy has gained momentum as a necessary precondition and indicator of a well-functioning healthcare system that prevents, manages, and treats disease. An April 2019 , simple search on Google Scholar shows a total of 217,000 results for the term "health literacy," with only 99,200 results for "media literacy" and 49,900 results for "science literacy" through similar searches.

In an attempt to clarify and coalesce global public health and medical sciences academics and practitioners around health literacy, various definitions have permeated the literature. These definitions are focused in two areas: (1) health literacy as a continuum between high or low levels of literacy; and (2) health literacy as a multidimensional concept focused on the interaction of skills within broader social and cultural contexts [5]. This divergence had resulted in lack of unity around a common definition of health literacy [6]. Notwithstanding definitional agreement, reviews of the health literacy literature conclude Ratzan and Parker's aforementioned definition has been the most cited [3,6]. Within the U.S., this definition has been adopted by the Department of Health and Human Services, the National Academies of Sciences, Engineering, and Medicine (formerly the Institute of Medicine), and the National Library of Medicine $[3,7,8]$. It also was the definition used in the U.S. Patient Protection and Affordable Care Act of 2010 [9].

The natural question is: to what extent are varying definitions consequential for accelerating action and progress in improving health literacy among disparate global populations? The authors contend an approximate definition is adequate for moving the field from definitional semantic debates to sustained 
practical action on health literacy. In the next section, we review past developments in public health clinical practice and policy reforms to provide a foundation for accelerated action on health literacy.

\section{Public health clinical practice and policy reform: building on progress}

The term health literacy was first used in 1974 to describe the impact of health education on both healthcare and education systems and outcomes [10]. Since then, various models (such as functional, interactive, and critical health literacy) have been proposed to identify and delineate and relationship between health literacy and the healthcare and education systems [11,12]. The integration of health literacy into public health and clinical care practice has led to progress in developing health literacy into a field that interacts with the healthcare and education systems. The latter has entailed cataloguing the problem, proposing definitions, encouraging health literacy as a mechanism to decrease healthcare costs, improving the quality of healthcare, and reducing disparities. It also resulted in assessment tools for measuring health literacy [13].

More recent efforts to promote health literacy commenced in the early 2000s. In 2004, the U.S. Institute of Medicine summarized the medical literature on health literacy to establish that: "efforts to improve quality, reduce costs, and reduce disparities cannot succeed without simultaneous improvements in health literacy" [8]. The Institute of Medicine additionally proposed a model to describe how individual health literacy skills can be influenced by culture and society as well as the health and educational systems [8].

In 2006, the first health literacy assessment tool was developed; the U.S. National Assessment of Adult Literacy [13]. This served to collect longitudinal data on the health literacy of adults living in the U.S. These early academic efforts eventually were integrated into public health education. One example is Columbia University's Mailman School of Public Health, which proposed a "Public Health Oath" in 2008. This oath articulated the professional commitment and guiding principles for students, graduates, and faculty in public health. It explicitly called out health literacy: "I will advance health literacy for all and seek equity and justice for vulnerable populations" [14].

As health literacy gained momentum in academia, it also infiltrated national health policy reform. A "blueprint for change" to achieve a health-literate America was proposed in 2003. This included four policy-oriented strategies to advancing health literacy: (1) research and measurement; (2) reducing health disparities; (3) engaging the federal government; and (4) improving medical practice [15]. These efforts led to Louisiana becoming the first U.S. state to pass health literacy improvement legislation in 2002 [16].

While a majority of the literature and policymaking on health literacy has occurred within the U.S., advances in other parts of the world have occurred. Although 15 percent of the literature on health literacy has been generated in the European Union (EU), the European Centre for Disease Prevention and Control (an agency of the European Union) actively promotes health literacy [17,18]. In response to the EU's public consultation on a legal proposal to provide health information to patients, the European Federation of Pharmaceutical Industries and Associations (EFPIA) (a coalition of national associations and pharmaceutical companies leading the research-based pharmaceutical industry in Europe) advanced the need to place product information within a broader context to improve health literacy $[18,19]$. In the United Kingdom (UK), the UK Committee on Safety of Medicines highlighted the importance of health literacy in identifying and communicating health information to make informed health decisions [19]. In 2009, the United Nations Economic and Social Council (ECOSOC) held a regional meeting on health literacy in Beijing, China and later issued a declaration exploring ways to strengthen multisectoral collaboration at the national, regional, and international levels. This was intended to undertake joint 


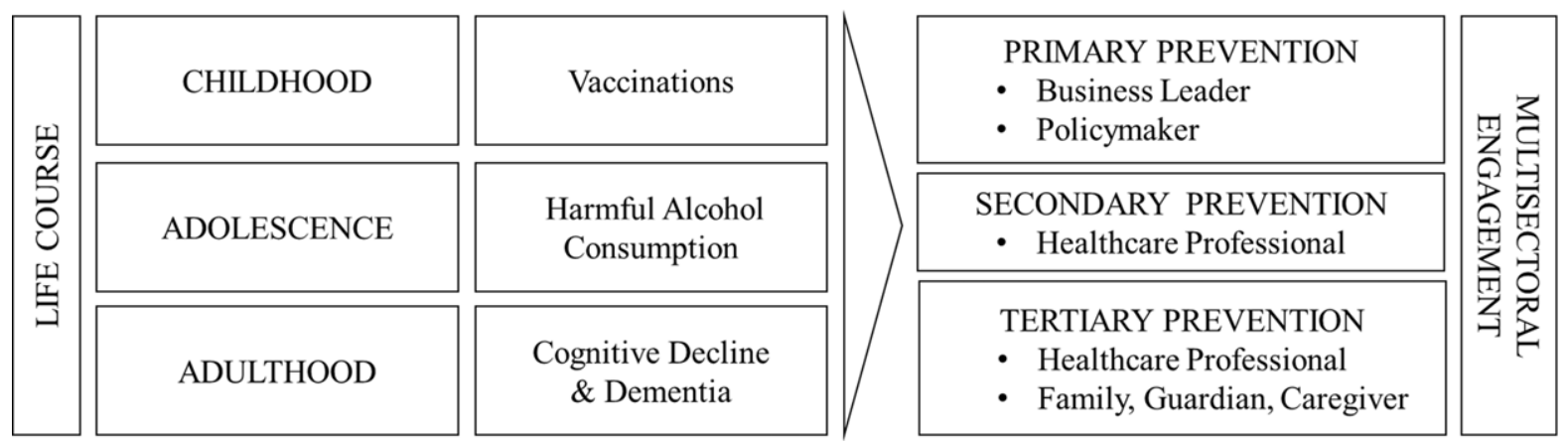

Fig. 1. Health literacy across the lifespan.

actions to increase health literacy; find ways to promote better access and use of information through information and communication technology and empowerment; and build capacity for sustained action to increase health literacy [20]. More recently in South East Asia, the World Health Organization (WHO) regional office released a health literacy toolkit for LMICs that focuses on integrating health literacy into policymaking processes [20].

While the diffusion of health literacy into public health clinical practice and national policy reforms has led to a productive expansion of the field, the authors believe the time is now to build on past progress. The authors suggest it is important to move health literacy beyond its public health and clinical origins to facilitate broader global impacts. In doing so, we propose a life course for health literacy.

\section{Ubiquitous health: a life course approach for health literacy}

Low health literacy has been associated with poorer health outcomes, increased risk of mortality, and unnecessary use and costs of healthcare services [21]. Unfortunately, individuals with low literacy have a poorer understanding of behaviors to promote health and disease management. Individuals with low health literacy also are less likely to use preventive services compared to individuals with average or above average literacy [15]. As one example, a U.S. national survey on health literacy skills concluded 85 percent of individuals cannot calculate an employee's share of health insurance costs using a table, while more than one-third of adults are uncertain as to how to take prescription medicines based on instructions on container labels [15].

In order to improve health and well-being outcomes as well as reduce healthcare costs, the authors propose a life course approach for health literacy. This requires dedicated efforts to promote health literacy across the lifespan. Realizing that each stage of life represents a spectrum of health and different levels of interaction with the healthcare system, the capacity for health literacy should be developed from before birth through childhood, adolescence, adulthood, and old age. For example, an older adult with multiple co-morbidities will use healthcare services differently than a younger individual. Figure 1 demonstrates a continuation of health literacy across the lifespan. It depicts a life course approach with three cases: childhood vaccinations, harmful alcohol consumption in adolescence, and cognitive decline and dementia in adulthood and older age.

The authors also provide examples of the stakeholders required to improve health literacy in each of the examples shown in Fig. 1. Primary prevention, or 'staying healthy' via intervention before health effects 
arise, commonly requires the engagement of health leaders such as policymakers and business leaders. They are frequently responsible for introducing measures that boost access to vaccinations or reduce access to alcohol. Secondary prevention - screening to early detect diseases before signs and symptoms often resides with healthcare professionals operating in clinical settings such as a hospital or clinic. The healthcare professional engages in activities such as mammography and blood pressure testing to screen for diseases. Lastly, tertiary prevention - managing disease to prevent or slow progression - requires the involvement of healthcare professionals along with a caregiver, such as a family member or guardian. The interaction and collaboration of these stakeholders across the lifespan demonstrates the need for multisectoral engagement in health literacy.

In partnership with the stakeholders outlined in Fig. 1, diverse strategies have been proposed to advance health literacy across the lifespan. These strategies cover the education, healthcare, business, and policy sectors. They are cross-disciplinary, cross-cutting, and cross-cultural, and have potential to accelerate efforts to improve health literacy in the coming decades. Table 1 presents a summary of these potential strategies for advancing health literacy.

Finally, it is worth noting the general semantic differences needed to more precisely describe health literacy. For example, the authors contend: (a) vaccine literacy is different from health literacy for vaccines; (b) alcohol literacy is different from health literacy for alcohol; and (c) dementia literacy is different from health literacy for dementia. The distinctions highlight the challenges posed by each of these life events, which require broader communication strategies to meaningfully engage multiple stakeholders to develop and integrate comprehensive 'health information and services needed to make appropriate health decisions.' This novel approach to health literacy is more than simply addressing healthcare or education systems. It includes partnerships with the public and private sector, along with academia and civil society.

\subsection{Early childhood vaccinations: vaccine literacy}

The leading public health achievements of the 20th Century include the global decline in vaccinepreventable deaths. Since 1792 when the first vaccination was developed, smallpox has been eradicated, child mortality has declined, and numerous birth disabilities have been prevented in many parts of the world [22].

However, these global health gains are threatened by rapid increases in vaccine hesitancy - defined as "the delay in acceptance or refusal of vaccines despite availability of vaccination services" - that has progressed in many countries [24]. The threat of vaccine hesitancy is so urgent that the WHO ranked it as a top ten health threat for 2019, alongside climate change, non-communicable diseases (NCDs), and high-threat pathogens such as Ebola [23].

While anti-vaccine statements date back to the 1800 s, more recent sentiments stem from now debunked evidence regarding the relationship between childhood vaccines and autism. This relationship initially was proposed by the British physician Andrew Wakefield and was published in a prestigious medical journal, The Lancet, in 1998. Nonetheless, the study included serious methodological flaws. Among them were a sample size of only 12 participants and no control group. The British Medical Journal later exposed the fraud and subsequent scientific reports show no causal relationship [25]. Despite no association, antivaccine sentiments have expanded beyond vaccines for measles, mumps, and rubella (MMR) to include human papilloma virus (HPV) and influenza [26]. U.S. states with medical and philosophical exemptions for childhood vaccines have reported declines in vaccine coverage [27].

A growing anti-vaccine movement is aligned with the proliferation of social media platforms that can propagate misinformation — such as Facebook, Twitter, and YouTube [28]. In 2018, Russian-operated 
Table 1

Potential strategies for future health literacy advancement

\begin{tabular}{|c|c|c|c|}
\hline & Category & Change agent(s) & Goals \& Tactics \\
\hline \multirow[t]{2}{*}{ Education } & $\begin{array}{l}\text { Capacity for critical thinking and } \\
\text { skill development }\end{array}$ & Primary and secondary educators & $\begin{array}{l}\text { High-school graduates equipped } \\
\text { with literacy, numerical, and other } \\
\text { skills to understand and evaluate } \\
\text { health information }\end{array}$ \\
\hline & Evaluation of research & Colleges \& universities & $\begin{array}{l}\text { Baccalaureate degree holders } \\
\text { understand limitations of scientific } \\
\text { methods and can assess the } \\
\text { strength of scientific evidence }\end{array}$ \\
\hline \multirow[t]{2}{*}{ Healthcare } & $\begin{array}{l}\text { Patient engagement on value of } \\
\text { prevention }\end{array}$ & $\begin{array}{l}\text { Physicians, nurses, and other } \\
\text { healthcare professionals }\end{array}$ & $\begin{array}{l}\text { Healthcare professional engages } \\
\text { with patients on the value of } \\
\text { primary prevention such as } \\
\text { modifiable behavioral risks and } \\
\text { vaccinations }\end{array}$ \\
\hline & $\begin{array}{l}\text { Educational training on cognitive } \\
\text { decline and dementia }\end{array}$ & $\begin{array}{l}\text { Physicians, nurses, and other } \\
\text { healthcare professionals; family, } \\
\text { guardians, caregivers }\end{array}$ & $\begin{array}{l}\text { Online educational training for } \\
\text { healthcare professionals and } \\
\text { caregivers to be fully equipped to } \\
\text { support individuals with cognitive } \\
\text { decline and dementia }\end{array}$ \\
\hline \multirow[t]{2}{*}{ Business } & $\begin{array}{l}\text { Access to preventive healthcare } \\
\text { services }\end{array}$ & Retailers & $\begin{array}{l}\text { Offering of preventive services } \\
\text { with educational materials in retail } \\
\text { clinics, pharmacies, schools, and } \\
\text { elsewhere }\end{array}$ \\
\hline & $\begin{array}{l}\text { Technological platforms for } \\
\text { engagement in health }\end{array}$ & Technology platforms & $\begin{array}{l}\text { Development of technologies with } \\
\text { adequate privacy controls and } \\
\text { cultural adaptation to enable } \\
\text { engagement in health outside of } \\
\text { hospital }\end{array}$ \\
\hline \multirow[t]{2}{*}{ Policy } & $\begin{array}{l}\text { Legislation to support health } \\
\text { activities }\end{array}$ & $\begin{array}{l}\text { Federal, state, and local } \\
\text { policymakers }\end{array}$ & $\begin{array}{l}\text { Legislation to further prevent } \\
\text { access to alcoholic beverages } \\
\text { combined with education for } \\
\text { adolescence }\end{array}$ \\
\hline & Caregiver compensation & State policymakers & $\begin{array}{l}\text { Legislation to offer tax credits to } \\
\text { unemployed caregivers }\end{array}$ \\
\hline
\end{tabular}

bots were found to promote discord and disinformation to sway vaccine sentiments on Twitter [29]. Although many people turn to their healthcare provider to access vaccine-related information, evidence suggests vaccine-hesitant parents are more likely to look to the Internet for information [30]. As a result, the proliferation of dysfunctional content has fostered increased vaccine hesitancy, delay, and refusal. The authors suggest the companies that operate social media platforms have a responsibility to filter misleading information on vaccines to promote population coverage [31].

Until now, the response to vaccine hesitancy has been articulated through disease prevention goals focused on developing 'herd immunity' within a population. Coined in 1923, the term refers to the percentage of vaccinated individuals required to protect an entire community (or herd) from a disease. 


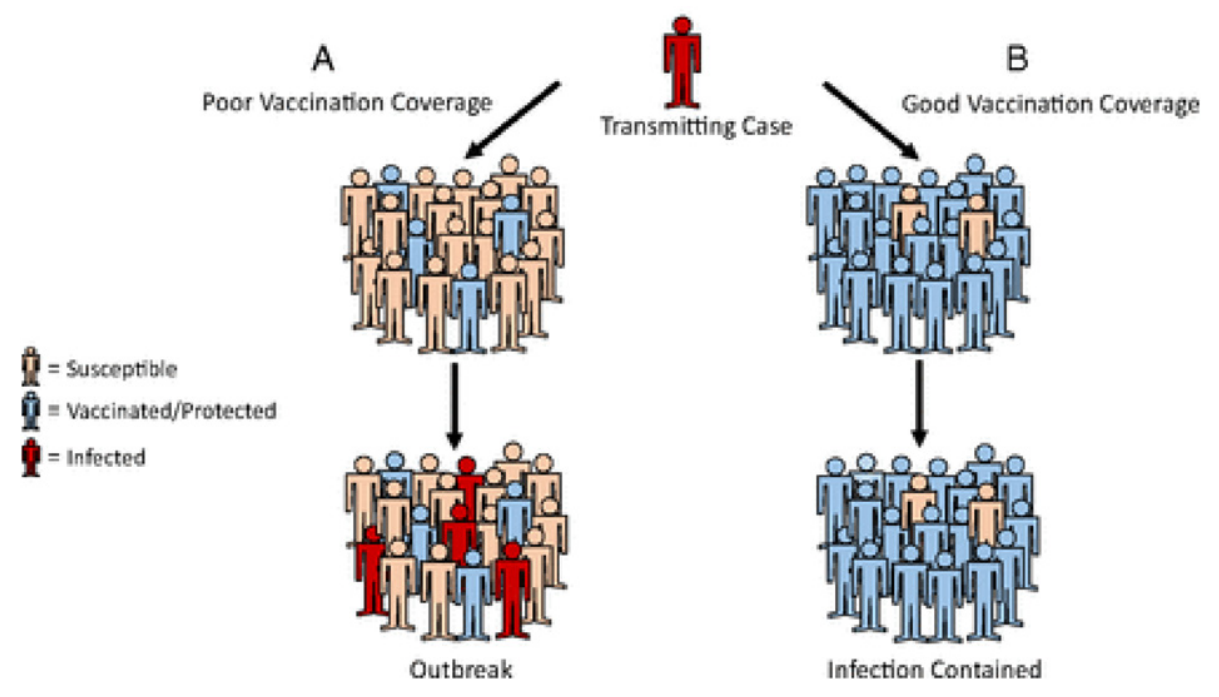

Fig. 2. Community protection.

For measles, herd immunity requires a 95 percent immunization rate in order protect a community. This means two doses of measles vaccine (to be 97 percent effective), while one dose is effective 93 percent of the time [32]. As vaccine hesitancy continues to gain momentum, calls have been made to shift from a focus on herd immunity to one centered on community protection $[31,33]$. Community protection entails individual protection for people who are vaccinated as well as reducing the spread of the disease within a population [34]. Figure 2 (which is adapted from the Proceedings of the National Academies of Sciences) demonstrates the effect of community protection within a population [34].

(A) represents a highly susceptible population, whereby a transmitting case will likely encounter a susceptible person. This will lead to a line of person-to-person transmission, and eventual outbreak.

(B) represents an immune population with good vaccination coverage. A transmitting case will likely not encounter a susceptible person. This breaks the line of transmission, yielding indirect protection of the remaining people who are susceptible.

Vaccine literacy can play an effective role in combatting anti-vaccine sentiments and to improve vaccine coverage among parents and their children [35]. Vaccine literacy entails improving the strength of systems that place value on both knowledge of the benefit and importance of vaccines in addition to promoting and integrating vaccines within a functioning health delivery system [36]. Building on previous efforts proposed by Parker, the authors contend vaccine literacy is composed of three interrelated elements: the individual and system that provides for skills, ability and knowledge to get vaccinated; simpler and stronger healthcare and education systems that generate demand for vaccines; and accelerated leadership and investments in digital health and communications to increase vaccine coverage as a social norm throughout the world.

\subsection{Adolescent health: alcohol literacy}

The WHO estimates that three million people died from alcohol in 2016, representing one in 20 deaths worldwide [37]. More than 75 percent of these deaths were among males, with a majority occurring in high-income countries, primarily Europe and the Americas [37]. Adolescents are especially affected; an 
estimated 27 percent of individuals between 15 and 19 years of age (totaling 155 million adolescents) drink alcohol globally [37]. School surveys suggest alcohol use commences before the age of 15 among males and females in many countries [37]. This can contribute to the onset of many NCDs in later life, such as cardiovascular disease, type 2 diabetes, and various cancers, as well as poor mental health, including depression and anxiety, across the life course [38].

Government policies have shown to be effective to curb alcohol intake. Common strategies include: increasing taxation on alcoholic beverages; restricting advertising across multiple types of media; and limiting access to alcohol in retail outlets [37]. Despite the demonstrated effectiveness of these policy interventions, the implementation of these policies by governments has varied among countries and has been piecemeal in its approach [37].

The field of alcohol literacy is emerging to address challenges associated with adolescence and harmful alcohol use. Alcohol literacy encourages better understanding of the risks by the broader public that are associated with binge alcohol consumption from adolescence through adulthood [37]. Although the relationship between health literacy and alcohol intake is poorly defined, the initial evidence suggests a positive correlation [39,40]. As an example, one study assessed individuals with Type 1 diabetes between the ages of 18 and 30. Among this group, it was found alcohol consumption was common, though knowledge of alcohol and carbohydrate content was limited [41]. The study highlights the importance of labeling and communications in improving alcohol health literacy. Similarly, other research suggests the importance of communication on alcohol consumption with health professionals rather than technological platforms to better understand alcohol risks [42].

\subsection{Cognitive decline in older ages: dementia literacy}

Changing demographics characterized by increased life expectancy and decreased fertility rates contribute to an aging global population. By 2050, one-fifth of the world's population will be more than 60 years old [43]. Rates of cognitive decline and other dementias are predicted to increase simultaneously. In the U.S., the Centers for Disease Control and Prevention (CDC) estimates that Alzheimer's and related dementias will double by 2060 [44].

Moreover, the economic toll of Alzheimer's disease and related dementias is significant and growing. In the U.S., Alzheimer's disease cost \$259 billion per year in 2017, with U.S. Medicare and Medicaid spending more than $\$ 175$ billion linked to its consequences [45]. At least 50 percent of Americans living with Alzheimer's disease remain undiagnosed, while less than half of people who have the disease have been told of their diagnosis [46]. Unfortunately, these statistics are not significantly different outside of the U.S. Internationally, there is a pervasive and troubling stigma associated with Alzheimer's disease.

In the past few years, scientific progress has been made to treat Alzheimer's disease. There is a better understanding of Alzheimer's biomarkers, including $\beta$-amyloid, tau protein, and neurodegeneration. Nevertheless, effective commercially biomedical treatments remain unavailable for Alzheimer's disease [47].

Alzheimer's economic toll is combined with its social burden. In both the U.S. and other countries facing an aging population such as the UK, as well as many parts of Europe and Japan, there are growing concerns about the social and economic burdens of unsupported caregiving. Close to 18 million family and unpaid caregivers support Americans with disabilities [48]. Caregivers are often females (as much as 75 percent), who provide caregiving for senior family members (and others) in addition to employment and child caregiving [49,50].

While diverse nations grapple with the challenges associated with delivering improved dementia prevention, care, and caregiving, the U.S. state of Massachusetts provides a current example of policy 
leadership. Massachusetts is the first U.S. state to modify state laws to support caregiving. In 2018, the Massachusetts legislature passed a multifaceted bill titled "An Act Relative to Alzheimer's and Related Dementias in the Commonwealth" (H.4116) [51]. Broadly, the law grants additional support to individuals, healthcare professionals, and caregivers who provide dementia care. Realizing that healthcare providers are in a unique position to diagnose and provide quality care to those with dementia, the Massachusetts Act requires formal training for healthcare professionals that interact with patients with various forms of dementia. The training is delivered through continuing medical education programs. In time, training will be required as part of license renewals for medical professionals, including physicians, physician assistants, registered nurses, and licensed nurse practitioners [46]. Beyond training, the law mandates clinicians "report the diagnosis to a family member or legal personal representative of the patient" and offer information on care planning, treatment, and support services [51].

In addition to legislative activities, new technologies can support older adults and their caregivers. Some initial research suggests voice interfaces have the potential to recognize vocal biomarkers of changes in a person's neurological or mental health status, aiding with broader diagnostic support [52]. Amazon's "Alexa" - a socially assistive robot - provides an example where older adults have interacted directly with the technology to improve social well-being in the home. Conversely, these technologies are poorly integrated into the healthcare system and often are used independently of the system or a caregiver [52].

\section{Future directions for health literacy: strategic opportunities}

Realizing that health literacy should be developed across the lifespan, the authors propose the creation of a new area of focus called dementia literacy that equips policymakers, healthcare professionals, business leaders, and employees with the tools to better navigate appropriate courses of action for cognitive decline and dementia care. This may include offering training that could include certification for caregivers by employers and education providers [48]. The training additionally should advance data collection regarding the prevalence of caregiving by individuals [49].

While the aforementioned ideas highlight three examples for action, this section provides strategic opportunities and future directions to improve health literacy. In particular, the expansion of treatment and caregiving requires data and technology through new mobile health tools as well as multisectoral engagement through collaborative partnerships.

\subsection{Digital health: data \& technology}

eHealth literacy has been proposed to capture health literacy in a digital context. eHealth literacy refers to "the ability to seek, find, understand, and appraise health information from electronic sources and apply the knowledge gained to addressing or solving a health problem" [53]. While this definition is predicated on health literacy in the context of electronic medical records, the authors contend there are other opportunities to apply data and technology to improve health literacy.

The emergence of personal, predictive, and preventive mobile technologies enables consumers to take control of their health through quantified tracking and monitoring. These mobile technologies range from wearables to remote monitoring devices to care coordination technologies predicated on artificial intelligence. For consumers, these technologies foster the passive tracking of one's health outside of a hospital setting. For physicians, mobile technologies enhance a provider's ability to use data and technology to help inform diagnosis and treatment of complex and costly diseases [54]. 
Although public health has traditionally focused on data-driven, epidemiological methods for drawing conclusions, the authors propose integrating insights from design thinking to improve health literacy using data and technology [55]. Stanford's d.school has identified five steps to design tools and technologies using design thinking. These include: (1) empathize by developing a deep understanding of the problem; (2) define the problem you want to solve; (3) ideate by brainstorming potential solutions; (4) develop a prototype to design and test various components of the solution; and (5) engage in short testing process to refine the solution [56]. A component of this process entails understanding, testing, and refining design features with end users of different ages, cognitive abilities, and socioeconomic status. This ensures that the solutions developed align with the needs and abilities of end users.

A practical example is The Mental Health Bridges Project, which proposes various guiding practices to design technological interfaces for individuals with poor mental health. These range from using vivid, warm colors and consistent formatting; including infographics; incorporating videos, audios, and images of 'people who look like me' and role models; and making the web pages printable [57]. At its core are design principles used to develop technological solutions that are appropriate for a target population's health literacy. The latter ensures information is delivered at the right time, to the right people, with the intended effect [58].

Despite the proliferation of these technologies, it is important to note that many individuals do not reap their benefits. The latter often stems from poor design or unaffordability. Individual privacy and confidentiality additionally can be invaded, leading to microtargeting or discriminating against various population segments [54]. Strong regulations combined with actions by technology companies can serve to address these challenges.

\subsection{Multisectoral engagement}

During the past two decades, partnerships have guided the development of health literacy as a discipline and field of study. These have been primarily academic and public sector collaborations. Nevertheless, decades of distrust between the public and private sectors - specifically big food, tobacco, alcohol, and pharma - has inhibited cross-sector collaborations to better health and well-being.

Years of documented evidence on activities to undermine the health efforts by government and public health institutions has led to the public sector largely viewing the private sector with suspicion. As Dr. Margaret Chan, the former Director General of WHO said: "Few governments prioritize health over big business ... efforts to prevent noncommunicable diseases go against the business interests of powerful economic operators" [61].

However, the authors suggest this scenario is starting to change. The burden of development action and finance can no longer rest on national governments and philanthropic institutions. In turn, the private sector and civil society is part of the multidimensional efforts to achieve the 2030 Global Agenda. The SDGs explicitly call for multisectoral - including private sector - engagement. Indeed, SDG 17 focuses on the formation of 'Partnerships for the Goals' to strengthen implementation and revitalize global partnerships [2].

Given the history of mistrust among these sectors, an interdisciplinary collaborative at the MossavarRahmani Center for Business and Government at the Harvard Kennedy School released a set of guiding principles to serve as a frame of reference for multisectoral engagements to achieve SDG3. These principles recognize health as a public good, and are driven by evidence, science, and values [62].

The seven guiding principles (depicted in Fig. 3) include: (1) agree on shared mission and goals in alignment with targets identified in health-related SDG targets; (2) ensure alignment of interests related to 


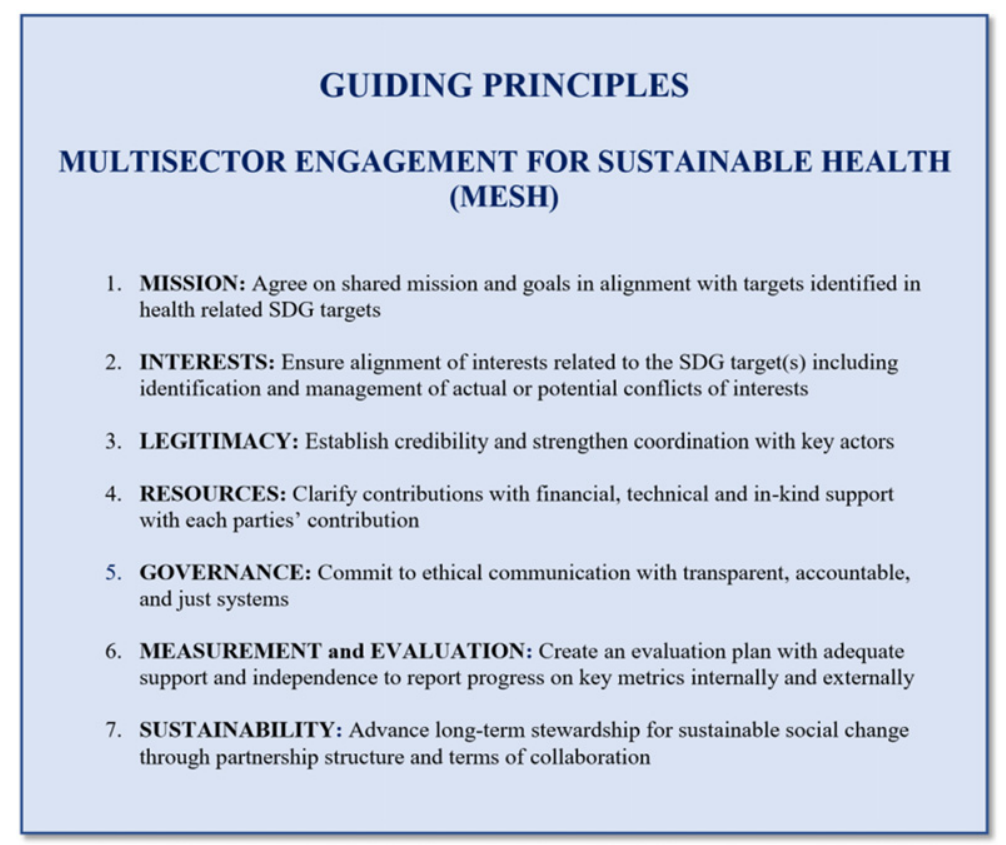

Fig. 3. Guiding Principles for Multisectoral Engagement for Sustainable Health (MESH).

the SDG target(s), including identification and management of actual or potential conflicts of interests; (3) establish credibility and strengthen coordination with key actors; (4) clarify contributions with financial, technical and in-kind support with each parties' contribution; (5) commit to ethical communication with transparent, accountable, and just systems; (6) create an evaluation plan with adequate support and independence to report progress on key metrics internally and externally; and (7) advance long-term stewardship for sustainable social change through partnership structure and terms of collaboration [62]. The authors contend these principles can guide productive collaborations between the public, private, and academic sectors to promote health literacy in the U.S. and globally.

Integrating these principles into future multisectoral engagements on health literacy in support of SDG3 will help facilitate the shift from improving individual health literacy among patients in clinical care settings to encouraging broader systems-level change.

\section{Conclusion: a call to action for advancing health literacy}

However ambitious, the 2030 Agenda for Sustainable Development is attainable with dedicated and concerted action. For the global community to achieve the health-related targets and indicators of the SDGs, health literacy must be integrated in new ways that build on past achievements.

Since the turn of the 20th century, the essential building blocks for health literacy have been established. There has been substantial growth in the academic literature on health literacy, which establishes the scientific evidence and credibility of the field. Definitional debates have defined the core of health literacy, along with other considerations on offshoots. Policy agendas in both the U.S. and other countries have included health literacy to advocate its deeper integration into healthcare and education sectors. These are 
all important accomplishments to elevate health literacy as an area of activity and action among academic and policy professionals within public health and the medical sciences.

The next twenty years augur leveraging existing progress to expand the influence of health literacy. In this chapter, the authors propose ideas on how this may be accomplished. First, we believe a life course is necessary for health literacy, one that spans life from before birth through death. Specifically, this means coalescing efforts within three areas where health literacy is critical: vaccinations in childhood, alcohol consumption in adolescence, and cognitive decline and dementia in adulthood and old age. Each of these phases of life should integrate health literacy through primary, secondary, and tertiary prevention efforts.

Second, new mobile technologies and digital communication tools should include guiding practices from health literacy. These tools and technologies have the potential to deliver healthcare at scale to improve outcomes and reduce costs. Yet, efforts to improve health are unlikely to succeed without thoughtful design to develop easy-to-navigate interfaces and protocols for data privacy and confidentiality. These technologies should be engineered using principles from design thinking, with collaborators across schools of engineering and healthcare.

Finally, multisectoral engagement is essential to facilitate the proliferation of health literacy beyond public health and the medical sciences. This requires leaders in academia and policymaking to interact with business, multilateral organizations, and civil society. Realizing the potential for competing priorities and conflicting interests, some guiding principles have been proposed. In addition, metrics inclusive of evaluation frameworks should be developed to determine the extent to which these partnerships promote health literacy and other indicators of the SDGs.

Gains in health literacy will not be realized simply through individual actions. It will be systems working in harmony that facilitate improvements in health and well-being for families, communities, and countries. The time is now for health literacy to move beyond the bench and bedside in clinical practice to achieve the aspirations and objectives of the 2030 Agenda for Sustainable Development. We look forward to making this a reality.

\section{References}

[1] World Health Organization, Ottawa Charter for Health Promotion, 1986, https://www.who.int/healthpromotion/ conferences/previous/ottawa/en, Retrieved April 6, 2019.

[2] United Nations, Sustainable Development Goals, 2016, https://www.undp.org/content/undp/en/home/sustainabledevelopment-goals.html, Retrieved April 6, 2019.

[3] C. Selden, M. Zorn, S. Ratzan and R. Parker, Health literacy, National Institute of Health, National Libraries of Medicine, 2000.

[4] World Health Organization, \#HealthInSDGs, 2016, https://www.who.int/healthpromotion/conferences/9gchp/policybrief4-health-literacy.pdf, Retrieved April 6, 2019.

[5] L. Mårtensson and G. Hensing, Health literacy - a heterogeneous phenomenon: a literature review, Scand J Caring Sci 26: (2012), 151-160. doi:10.1111/j.1471-6712.2011.00900.x.

[6] A. Huhta, N. Hirvonen and M. Huotari1, Health literacy in web-based health information environments: systematic review of concepts, definitions, and operationalization for measurement, J Med Internet Res 20 (2018), e10273. doi:10.2196/10273.

[7] Department of Health and Human Services, Healthy People 2010: Understanding and Improving Health, 2nd ed. National Academies Press, Washington DC, 2010, pp. 21-39.

[8] Institute of Medicine. Health Literacy: A Prescription to End Confusion, Washington DC, 2004.

[9] Department of Health and Human Services. Patient Protection and Affordable Care Act of 2010, Washington DC, 2010.

[10] S. Simonds, Health education as social policy, Health Edu and Behav 2: (1974), 1-10. doi:10.1177/10901981740020S102.

[11] D. Nutbeam, Health literacy as a public health goal: a challenge for contemporary health education and communication strategies into the 21st century, Health Promot Int 15: (2000), 259-267. doi:10.1093/heapro/15.3.259. 
[12] S. Ratzan, Health literacy: communication for the public good, Health Promot Int 16: (2011), 207-214. doi:10.1093/ heapro/16.2.207.

[13] D. Nutbeam, The evolving concept of health literacy, Soc Sci Med 67: (2008), 2072-2078. doi:10.1016/ j.socscimed.2008.09.050.

[14] Columbia University Mailman School of Public Health, Public health oath, 2008, https://www.mailman.columbia. edu/about/mission-history/public-health-oath, Retrieved April 6, 2019.

[15] S. Ratzan, N. Lurie and R. Parker, Health literacy: a policy challenge for advancing high-quality health care, Health Aff 22: (2003), 147-153. doi:10.1377/hlthaff.22.4.147.

[16] R. Parker and S. Ratzan, Health literacy: a second decade of distinction for Americans, J Health Commun 15(Suppl 2) (2010), 20-33. doi:10.1080/10810730.2010.501094.

[17] G. Quaglio, K. Sørensen, P. Rübig, L. Bertinato, H. Brand, T. Karapiperis, I. Dinca, T. Peetso, K. Kadenbach and C. Dario, Accelerating the health literacy agenda in Europe, Health Promot Int 32: (2017), 1074-1080. doi:10.1093/heapro/daw028.

[18] European Centre for Disease Prevention and Control, Health literacy, 2019, https://ecdc.europa.eu/en/healthcommunication/facts/health-literacy, Retrieved April 6, 2019.

[19] Medicines and Healthcare Products Regulatory Agency, Always read the leaflet—getting the best information with every medicine, Committee on safety and medicines working group on patient information, London, UK, 2005.

[20] United Nations Economic and Social Council, Health literacy and the Millennium Development Goals: United Nations Economic and Social Council (ECOSOC) regional meeting background paper, J Health Commun 15(Suppl 2) (2010), 211-223. doi:10.1080/10810730.2010.499996.

[21] J. Vernon, A. Trujillo, S. Rosenbaum and B. DeBuono, Low health literacy: implications for national health policy, https://publichealth.gwu.edu/departments/healthpolicy/CHPR/downloads/LowHealthLiteracyReport10_4_07.pdf, Retrieved April 6, 2019.

[22] Centers for Disease Control and Prevention. Achievements in public health, 1900-1999 impact of vaccines universally recommended for children - United States, 1990-1998, 1999, https://www.cdc.gov/mmwr/preview/ mmwrhtml/00056803.htm, Retrieved April 6, 2019.

[23] World Health Organization, Ten threats to global health in 2019, 2019, https://www.who.int/emergencies/ten-threats-toglobal-health-in-2019, Retrieved April 6, 2019.

[24] World Health Organization, Report of the SAGE Working Group on Vaccine Hesitancy, 2014, https://www. who.int/immunization/sage/meetings/2014/october/1_Report_WORKING_GROUP_vaccine_hesitancy_final.pdf, Retrieved April 6, 2019.

[25] A. Wakefield, S. Murch, A. Anthony, J. Linnell, D. Casson, M. Malik, M. Berelowitz, A. Dhillon, M. Thomson, P. Harvey, A. Valentine, S. Davies and J. Walker-Smith, RETRACTED: Ileal-lymphoid-nodular hyperplasia, non-specific colitis, and pervasive developmental disorder in children, Lancet 351: (1998), 637-641. doi:10.1016/S0140-6736(97)11096-0.

[26] K. Intlekofer, M. Cunningham and A. Caplan, The HPV vaccine controversy, Virtual Mentor 14: (2012), $39-49$. doi:10.1001/virtualmentor.2012.14.1.msoc1-1201.

[27] Centers for Disease Control and Prevention, FastStats: immunization, 2017, https://www.cdc.gov/nchs/fastats/ immunize.htm, Retrieved April 6, 2019.

[28] C. Wardle and H. Derakhshan, Information disorder: toward an interdisciplinary framework for research and policy making, 2017, https://rm.coe.int/information-disorder-toward-an-interdisciplinary-framework-for-researc/168076277c, Retrieved April 6, 2019.

[29] D. Broniatowski, A. Jamison, S. Qi, L. AlKulaib, T. Chen, A. Benton, S. Quinn and M. Dredze, Weaponized health communication: Twitter bots and Russian trolls amplify the vaccine debate, Am J Public Health 10: (2018), 1378-1384. doi:10.2105/AJPH.2018.304567.

[30] E. Dubé, M. Vivion and N. MacDonald, Vaccine hesitancy, vaccine refusal and the anti-vaccine movement: influence, impact and implications, Expert Rev Vaccines 14: (2015), 99-117. doi:10.1586/14760584.2015.964212.

[31] L. Gostin, S. Ratzan and B. Bloom, Safe vaccinations for a healthy nation: increasing US vaccine coverage through law, science, and communication, JAMA (2019). doi:10.1001/jama.2019.4270 [Epub ahead of print].

[32] Centers for Disease Control and Prevention, Measles, mumps, and rubella (MMR) vaccination: what everyone should know, 2019, https://www.cdc.gov/vaccines/vpd/mmr/public/index.html, Retrieved April 6, 2019.

[33] S. Ratzan, Childhood vaccination must not become a wedge issue, Financial Times, 2019, https://www.ft.com/ content/1da58b76-6743-11e9-b809-6f0d2f5705f6, Retrieved April 6, 2019.

[34] W. Orenstein and R. Ahmed, Simply put: vaccination saves lives, PNAS 114: (2017), 4031-4033. doi:10.1073/pnas.1704507114.

[35] S. Ratzan, Vaccine literacy, a crucial healthcare innovation, Harvard Business Review, 2011, https://hbr.org/2011/ 02/vaccine-literacy-a-crucial-hea, Retrieved April 6, 2019. 
[36] S. Ratzan, Vaccine literacy: a new shot for advancing health, J Health Commun 16: (2011), $227-229$. doi:10.1080/10810730.2011.561726.

[37] World Health Organization, Global status report on alcohol and health 2018, 2018, https://www.who. int/substance_abuse/publications/global_alcohol_report/en, Retrieved April 6, 2019.

[38] J. Boden and D. Fergusson, Alcohol and depression, Addiction 106: (2011), 906-914. doi:10.1111/j.13600443.2010.03351.x.

[39] S. Ratzan, The future of health communication: innovating through partnerships, MÈTODE Sci Stud J 88: (2015), 11-17. doi:10.7203/metode.6.7096.

[40] D. Chisolm, J. Manganello, K. Kelleher and M. Marshal, Health literacy, alcohol expectancies, and alcohol use behaviors in teens, Patient Educ Couns 97: (2014), 291-296. doi:10.1016/j.pec.2014.07.019.

[41] K. Barnard, P. Dyson, J. Sinclair, J. Lawton, D. Anthony, M. Cranston and R. Holt, Alcohol health literacy in young adults with Type 1 diabetes and its impact on diabetes management, Diabet Med.31: (2014), 1625-1630. doi:10.1111/dme.12491.

[42] P. Tamony, R. Holt and K. Barnard, The role of mobile applications in improving alcohol health literacy in young adults with type 1 diabetes: help or hindrance?, J Diabetes Sci Technol 9: (2015), 1313-1320. doi:10.1177/1932296815588559.

[43] S. Chatterji, J. Byles, D. Cutler, T. Seeman and E. Verdes, Health, functioning and disability in older adults - current status and future implications, Lancet 385: (2014), 563-575. doi:10.1016/S0140-6736(14)61462-8.

[44] K. Matthews, W. Xu, A. Gaglioti, J. Holt, J. Croft, D. Mack and L. McGuire, Racial and ethnic estimates of Alzheimer's disease and related dementias in the United States (2015-2060) in adults aged $\geq 65$ years, Alzheimers Dement 15: (2019), 17-24. doi:10.1016/j.jalz.2018.06.3063.

[45] Alzheimer's Association, Costs of Alzheimer's to Medicare and Medicaid, 2018, http://act.alz.org/site/ DocServer/2012_Costs_Fact_Sheet_version_2.pdf?docID=7161, Retrieved April 6, 2019.

[46] Alzheimer's Association, The Mass Alzheimer's and Dementia Act, 2018, http://www.alzmassnh.org/files/uploads/2018/ 01/Massachusetts-Alzheimers-and-Dementia-Act-.pdf, Retrieved April 6, 2019.

[47] E. Largent and J. Karlawish, Preclinical Alzheimer Disease and the dawn of the pre-caregiver, JAMA Neurol (2019). doi:10.1001/jamaneurol.2019.0165 [Epub ahead of print].

[48] J. Burgdorf, D. Roth, C. Riffin and J. Wolff, Factors associated with receipt of training among caregivers of older adults, JAMA Int Med (2019). doi:10.1001/jamainternmed.2018.8694 [Epub ahead of print].

[49] J. Fuller and M. Raman, The caring company, 2019, https://www.hbs.edu/managing-the-future-of-work/ Documents/The_Caring_Company.pdf, Retrieved April 6, 2019.

[50] Institute of Aging, Read how IOA views aging in America, 2016, https://www.ioaging.org/aging-in-america, Retrieved April 6, 2019.

[51] Massachusetts Legislature, Bill HR 4116, https://malegislature.gov/Bills/190/H4116, Retrieved April 6, 2019.

[52] L. Evangelista, S. Steinhubl and E. Topol, Digital health care for older adults, Lancet 393 (2019), 1439. doi:10.1016/S01406736(19)30800-1.

[53] C. Norman and H. Skinner, eHealth literacy: essential skills for consumer health in a networked world, J Med Internet Res 8 (2006), e9. doi:10.2196/jmir.8.2.e9.

[54] G. Christie, K. Patrick and D. Yach, Guidelines for personalized health technology, 2016, thevitalityinstitute.org/site/wpcontent/uploads/2016/03/Guidelines-for-Personal-Health-Technology_March2016_FINAL.pdf, Retrieved April 6, 2019.

[55] M. Altman, T. Huang and T. Breland, Design thinking in health care, Prev Chronic Dis 15 (2018), 180128. doi: $10.5888 /$ pcd15.180128.

[56] Institute of Design at Stanford, An introduction to design thinking: process guide, 2010, https://dschoolold.stanford.edu/sandbox/groups/designresources/wiki/36873/attachments/74b3d/ModeGuideBOOTCAMP2010L.pdf, Retrieved April 6, 2019.

[57] National Academies of Sciences, Engineering, and Medicine, The intersection of behavioral health, mental health, and health literacy: proceedings of a workshop, https://www.nap.edu/read/25278/chapter/1, Retrieved April 6, 2019.

[58] S. Ratzan, Health literacy: communication for the public good, Health Promot Int 16: (2001), 207-214. doi:10.1093/heapro/16.2.207.

[59] World Health Organization, WHO Director-General addresses health promotion conference, 2013, https://www. who.int/dg/speeches/2013/health_promotion_20130610/en/, Retrieved April 6, 2019.

[60] S. Ratzan, A. Feigl, G. Christie, M. Sidibe, S. Bhatt, E. Gregor, C. LeComte and A. Skeath, Guiding Principles for Multisector Engagement for Sustainable Health (MESH), 2019, https://www.hks.harvard.edu/centers/mrcbg/ publications/awp/awp106, Retrieved April 6, 2019.

[61] United Nations, United Nations ministerial declaration, Geneva, Switzerland, 2009.

[62] D. Kahneman, Thinking Fast and Slow. Farrar, Straus Giroux, New York, NY, 2011. 